\title{
Understanding the choice of Chinese graduate students' English language learning in a Canadian post-secondary context
}

\author{
Wang, Huizhi \\ University of Saskatchewan, Canada (huizhi.wang@usask.ca) \\ Cottrell, Michael $\$ \\ University of Saskatchewan, Canada (michael.cottrell@usask.ca)
}

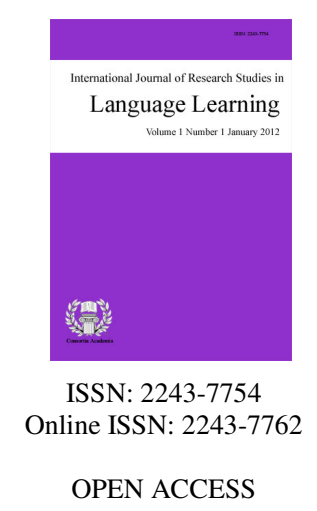

Received: 8 June 2015

Revised: 17 September 2015

Available Online: 9 February 2016

DOI: $10.5861 /$ ijrsll.2016.1262

Accepted: 2 November 2015

\section{Abstract}

This study explores the English learning strategies employed by Chinese graduate students before and after their arrival in Canada, to document and analyze shifts in strategic approaches to language acquisition in a specific context of post-secondary internationalization. Narrative inquiry data collection methods, framed by a qualitative co-constructivist theoretical paradigm, shaped the research. Themes emerging from data analysis suggested that participants' reliance on memory and cognitive strategies employed in China were abandoned in favor of utilization of compensation and social strategies after moving to Canada. Participants made these changes primarily because of their desire to make best use of the English-speaking Canadian environment to improve English proficiency, as an explicit and significant aspect of their personal motivations for internationalization. An important finding of this research is that immersion in the English-speaking environment inspired participants to employ different English learning strategies leading to significant improvement in English proficiency. The study seeks to address a gap in the research literature on internationalization and second language acquisition, in order to understand and mitigate the well-documented challenges experienced by international students in transitioning from one linguistic context to a dramatically different one.

Keywords: post-secondary students; internationalization; Chinese graduate students; English language learning strategies 


\section{Understanding the choice of Chinese graduate students' English language learning in a Canadian post-secondary context}

\section{Introduction}

Internationalization of higher education, defined as the process of integrating an international, intercultural, or global dimension into the purpose, functions and delivery of postsecondary education, has increased dramatically over the past two decades (Knight, 2003). This trend is likely to intensify as the globalization of commerce, social forces, idea exchange, and growth in student mobility drive further significant internationalization of education (Banks et al., 2007; Haddad, 2006). Because of its large population, growing affluence and appetite for an English language educational experience, Chinese students are currently among the most influential drivers of postsecondary internationalization globally (Zhou, 2012).

Linguistic competency has been identified by researchers as one of the main challenges inherent in the internationalization process as international students struggle to adjust to different cultural contexts and achieve academic success through instruction in a second or additional language. Since the largest flow of international students is to postsecondary institutions in English-speaking countries, most of these institutions require minimum levels of English language competency through standardized tests such as TOFEL or IELTS, as a condition of acceptance. But even when these requirements are met, it is generally understood that most international students will need to acquire greater mastery in English, including discipline-specific academic or professional terminology. For most international students, then, ongoing English language learning in English-speaking contexts is both a prerequisite for academic success and an explicit motivation for academic mobility. It is not clear from the research literature, however, whether different language learning strategies are required by virtue of this shift from a non-English speaking environment to an environment where English is both the first language and the language of instruction.

The purpose of this study is to explore the English learning strategies employed by Chinese graduate students before and after their arrival in Canada, to document and analyze possible shifts in strategic approaches to language acquisition in a specific context of post-secondary internationalization. We seek to address a gap in the research literature on internationalization and second language acquisition, in order to understand and mitigate the well-documented challenges experienced by international students in transitioning from a non-English speaking context to a context where English is the first language and the language of instruction. The study is guided by the following research questions:

$>\quad$ What strategies were employed by Chinese students to learn English in China and what were the reasons for their choice of language-learning strategies?

$>\quad$ What similar and different strategies were employed by Chinese students to learn English in Canada?

$>$ What are possible explanations for changes in approaches to English language learning in the Canadian context?

$>\quad$ What are the implications of this research for Chinese international students and English-speaking postsecondary institutions?

\section{Literature Review}

\subsection{Oxford's (1990) Classification}

There is general agreement that Oxford's (1990) taxonomy of Language Learning Strategies (LLS) is the most comprehensive, detailed, and systematic to date (Ellis, 1994; Vidal, 2002; Alhaisoni, 2012; Li, 2002; Magno, 2010; Mochizuki, 1999; Park, 1994). The system is divided into two general classes of LLS: direct and indirect. "These two classes are subdivided into a total of six groups: memory, cognitive, and compensation 
Understanding Chinese graduate students' English language learning in a Canadian post-secondary context

under the direct class; meta-cognitive, affective, and social under the indirect class" (Oxford, 1990, p. 14). When learners employ direct LLS, the target language must be involved directly with the learning process. However, when indirect LLS are used, the learners are aided in learning languages without directly involving the target language. Hong-Nam and Leavell (2006) provided the following definitions of the six categories: Memory Strategies for storing and retrieving information, Cognitive Strategies for understanding and producing the language, Compensation Strategies for overcoming limitations in language learning, Meta-cognitive Strategies for planning and monitoring learning, Affective Strategies for controlling emotions, motivations, and Social Strategies for cooperating with others in language learning (p. 403).

\subsection{Successful and Unsuccessful Language Learners}

Qingquan, Chatupote, and Teo (2008) noted that the relationship between the choice of LLS and language proficiency is not known, although a number of researchers have explored it (McIntyre, 1994; Bremner, 1999). However, no "precise formula for effective language learning exists" (Rivera-Mills \& Plonsky, 2007, p. 543). Researchers who probe successful LLS suggest that proficient language learners prefer to employ various LLS more than their peers with low proficiency (Green \& Oxford, 1995; Griffiths, 2008; Philips, 1991). Takeuchi (2003) analyzed the common features of Japanese citizens who had a good command of a foreign language and concluded that meta-cognitive strategies are valued by successful foreign language learners (in a Japanese context). Successful English users utilized deep LLS in memory and cognitive categories, such as "improving English through reading and looking for patterns in English" (Qingquan et al., 2008, p. 343). In contrast, surface strategies, such as "word-for-word translation and remembering English by repeating" (Qingquan et al., 2008, p. 343), were popular with unsuccessful English learners. Gan et al. (2004) stated that having a positive attitude plays a key role in language learning. Wong and Nunan (2011) suggested that using English for communicative purposes is valued by more effective learners.

\subsection{Strategies Employed by Chinese Students to Learn English in China}

English is considered to be the most popular global language in China (Pan \& Block, 2011) and the increasing number of English learners in China has given rise to a multitude of studies to probe the patterns of these English learners (Gao, 2006; Gisberg, 1992; Liu, 2007; Rao, 2002; Xu, 2003). The results of these studies show that methods widely-used by Chinese students center on employing memorization and repetition, and focusing on linguistic skills instead of communicative skills, depending on the preferences of their instructors.

\subsection{How Chinese Students Learn English after Studying Abroad}

Numerous studies suggest that immersion in an English-speaking environment contributes to English learners' English proficiency. Exposure to English develops learners' proficiency in speaking, listening, vocabulary, grammar, and it also improves their motivation to learn the target language (Cadd, 2012; Pellegrino, 2005; Segalowitz, Freed, Collentine, Lafford, Lazar, \& Diaz-Campos, 2004). However, without a strong effort by the learner, simply being immersed in an English-speaking environment fails to lead to the natural enhancement of English proficiency (Coleman, 1997). A strong individual effort is required because students need to generate output to make progress even in an input-rich environment (Storch \& Hill, 2008). Part of this effort for Chinese students should include the use of language learning strategies to learn the target language. These strategies enable them to rely on themselves--not on others, such as parents and teacher--to learn the target language.

Zhou's (2012) study of Chinese international students in Canada asserted that these Chinese students preferred to associate with other Chinese students and stay in Chinese communities, no matter how long they had been in English-speaking countries. However, the importance of socializing with native English speakers cannot be ignored because it plays a key role in enhancing English proficiency (Fischer, 2013; Rochecouste et al., 2012; Bakhtin, 1981). Ma and Li (2013) demonstrated how another group of Chinese students successfully reduced 
Wang, H., \& Cottrell, M.

language barriers while studying at an American university. The most popular learning strategy this group used to enhance their English proficiency was to have "more contact with natives to achieve more communication in English" (Ma \& Lin, 2013, p. 70).

The diary study conducted by Carson and Longhini (2002) revealed that "in the language immersion situation, a learner's strategies were variable over time" (p. 402). Kojic-Sabo and Lightbown (1999) concluded that in the ESL setting, students were more inclined to depend on themselves to incorporate new vocabulary from the English-medium environment and "showed a greater creativity in the selection of reviewing techniques, such as reviewing words in daily conversations" than EFL students (p. 183). Another prominent study conducted by Cubillos, Chieffo, and Fan (2008) focused on American students who were studying Spanish. The participants were divided into two groups: one studying in an English speaking context and the other in a Spanish immersion environment. Students immersed in the Spanish environment had a preference for meta-cognitive strategies. Also, they were more likely to employ social strategies, such as asking for other people's assistance, in understanding the content of the listening task.

The study conducted by Gao (2003) revealed that Chinese students changed the strategies they employed to learn vocabulary in order to meet the needs of changing contexts. In short, extant research suggests that LLS employed by international students in their home countries may not contribute to language learning after their arrival in foreign countries (Liu, 2011; Rochecouste et al., 2011; Storch \& Hill, 2008).

\section{Methodology}

Narrative inquiry data collection methods, framed by a qualitative co-constructivist theoretical paradigm, shaped the research. As a Chinese graduate student, the first author brought an emic perspective to the research. The second author supervised the research in fulfillment of a Master's of Education. Purposeful sampling techniques were employed to select six participants. These were full time Chinese graduate students, aged from 22-30 years old, three males and three females, who have resided in Canada for at least 6 months to allow for adaptation to the English-speaking environment. Some participants were enrolled in formal English language programs in Canada, while others sought to improve their English proficiency informally, by studying and living in the country. Data was collected through one-on-one semi-structured interviews followed by a focus group interview. Interviews were conducted in Chinese (Mandarin) since it was believed that greater insight could be achieved through accessing participants' narratives in their first language. After collecting data, the researcher transcribed the data, identified themes, and translated the data that the researcher quoted from Chinese into English. Accuracy of translation was ensured by employing a peer translator.

\subsection{Participants}

Participant A is a 23-year-old student who studies in a MBA program. Participant B is a 24-year-old student studying Biochemistry. Participant $\mathrm{C}$ is a 27-year-old doctoral student in a College of Public Health. Participant E is a 24-year-old student who is participating in a Chemical Engineering Master's Program. Participant F is also a 25 year old Masters of Engineering student. Participant G (23 years old) is enrolled in a Masters program in Geography.

\section{Findings and Discussions}

The researcher analyzed participants' narratives through Oxford's (1990) classification on language learning strategies. The narratives analyzed focused on participants' reflections on their English learning experiences in China and in Canada to identify both continuities and discontinuities in the strategies employed.

\subsection{Strategies Employed in China}

Based on their narratives participants of this study employed a variety of English learning strategies to 
Understanding Chinese graduate students' English language learning in a Canadian post-secondary context

improve their English proficiency in China. These English learning strategies are divided into six categories of strategies on the basis of Oxford's classification (1990). These include: memory strategies, cognitive strategies, meta-cognitive strategies, affective strategies, compensation strategies and social strategies. The two most popular strategies participants employed were cognitive strategies and memory strategies. Moreover, participants valued the importance of learning English from authentic English materials. They sought to improve English by watching English movies and TV shows, reading English books, listening to English songs, and playing English computer games. This strategy known as "practicing naturalistically", refers to "practicing the new language in natural, realistic settings" (Oxford, 1990, p. 45) as part of cognitive strategies. Furthermore, participants integrated meta-cognitive strategies into their preparation for English proficiency tests. For instance, they designed study plans and prepared for these tests on the basis of these plans.

Additionally, in China where there was a lack of an English-speaking environment, participants still made efforts to "seek practice opportunities" (Oxford, 1990, p. 139). A case in point was to consciously think in English. In addition, participants valued the importance of "cooperating with proficient users" (Oxford, 1990, p. 147). They also employed "reasoning deductively", a strategy for "using general rules and applying them to new target language situations" (Oxford, 1990, p. 46), to facilitate the acquisition of satisfactory scores in English tests. Moreover, confronted with huge stress on account of English proficiency tests, participants adopted affective strategies to cope with their negative feelings.

The Reasons for the Imbalances - An imbalance between linguistic details and communicative skills was a significant factor among participants' English learning process in China. These participants spent a large amount of time mastering English linguistic details but little time practicing communicative skills. They subsequently realized the importance of practicing English communicative skills. For example, Participant $\mathrm{C}$ engaged in an English corner to practice English communicative skills with peers. Participant F and Participant G conversed with their foreign teachers in English. However, these participants' English communicative skills were still impeded due to the EFL environment in China and the pressure of the English proficiency tests. Yang and Gai (2010) suggested that Chinese students' limited practicing of English communicative skills could be traced to the EFL learning environment in China. Similarly, in this study the EFL environment in China contributed to participants' limited exposure to an English-speaking environment. English proficiency tests were also responsible for participants' unsatisfactory acquisition of English communicative skills (Jin \& Yang, 2006; Pan \& Block, 2011). Most English proficiency tests in China focused on evaluating participants' ability regarding linguistic details but ignored their communicative skills. Consequently, to acquire satisfactory scores in these tests, participants had to sacrifice time spent practicing English communicative skills to concentrate on exercises related to linguistic details.

Strategies Used in Learning Vocabulary - The strategy "repeating" (Oxford, 1990, p. 45) was popular among participants who memorized English vocabulary. Scovel (1983) and Yu (1984) noted that Chinese students had a tendency for memorization and repetition in their English learning. Participants in this research also employed the strategy "repeating" to acquire a good command of English vocabulary. These participants' utilization of repetition as the primary method to learn English could be traced to English teachers' traditional pedagogical approaches. Before attending universities, high school English teachers told these participants that the most efficient way to master English vocabulary was to repeat reading or writing those words, and this was one of the major tasks in English classes and for after-class assignments. Consequently, repetition was deemed as an optimal way of learning English vocabulary by these participants. However, the strategies employed by these participants to master English vocabulary were not limited to repetition as they also valued the importance of the meanings of words and the contexts of using the words. Participant G learned new English words through discovering the roots, the prefixes, and the suffixes of words. Participants B, C, and E integrated learning English vocabulary by incorporating new information from texts or English stories.

Stress related to English Proficiency Tests - Most participants experienced huge stress while learning English in China because acquiring high proficiency in English facilitated these participants' inroads into further 
Wang, H., \& Cottrell, M.

education. In China, English proficiency tests were geared towards preparing students for entrance test from elementary school onwards. A case in point is the college entrance examination since the higher their scores in English proficiency tests, the more likely participants would be admitted into prestigious universities. Due to the pressure of English proficiency tests, some participants suffered from negative feelings of anxiety and frustration. These participants adopted affective strategies to deal with these negative feelings. Unlike the participants in Rao's (2006) study, the participants of this research listened to soothing music, sharing feelings with friends, and vented frustration through crying or throwing pens. These participants did not undertake any initiatives to prevent the negative feelings by encouraging themselves. Instead, they had to deal with these negative feelings when they felt anxious and frustrated.

The participants who studied English because of interest in Western culture were more likely to enjoy English learning despite the stress. Participant A was intrigued by English because she was interested in Western classical music and art. Participant B was curious about the differences between Chinese and English when she imitated English pronunciations from English movies. Participant F's interest in learning English could be attributed to his interest in English computer games. These participants enjoyed the process of improving their knowledge of English and Western culture although they often felt frustrated or stressed due to poor performance in English tests.

\subsection{Chosen Strategies in Canada}

It was clear from participants' narratives that their adjustment to the English-speaking environment in Canada was constrained by their inadequate English listening and speaking abilities. To overcome this challenge participants mainly used compensation strategies, social strategies, and meta-cognitive strategies. Compensation strategies were vital when they had difficulties in being understood or understanding what others said. Additionally, social strategies enabled participants to improve English by collaboration with others in Canada. Some participants also benefited from using meta-cognitive strategies. The strategy of "identifying the purpose of a language task" (Oxford, 1990, p. 139) facilitated Participant B's academic readings. Confronted with a large number of articles, Participant B read the abstract of an article before reading the main body of the article. She found the information she needed from the abstract and read the article with the purpose of seeking the corresponding parts with the information. Also, affective strategies enabled some participants to feel confident and to encourage themselves to practice speaking English in spite of making mistakes.

Explanations for Participants' Inadequate English Proficiency - Several researchers, such as Lee (1997), Lewthwaite (1996), and Senyshyn et al. (2000) have stated that international students' English improvement in English-speaking countries is impeded by their inadequate listening, speaking, reading, and note taking abilities, as well as by limited vocabulary. The insight also holds true for this research. Participants in this research encountered challenges adjusting to the English-speaking environment in Canada because they were not proficient in listening, speaking, and reading English and had not acquired sufficient vocabulary. However, in this research, some of these problems could be traced to these participants' English learning experience in China. The examination-centered system in China compelled participants to focus on the accuracy of the English they used. As a result, after these participants moved to Canada, they did not have the courage to converse with others in English as it required skills other than accuracy. In addition, the English these participants learned in China was formal and vocabulary was often outdated. But the English used by Canadians was informal and current. Consequently, when these participants interacted with Canadians, they had difficulty understanding what others said and frequently were unable to express their opinions accurately and appropriately.

Exposure to the English-speaking Environment - All participants agreed on the importance of making individual effort to be exposed to the English-speaking environment while staying in Canada. Without individual efforts, simply staying in an English-speaking environment would not facilitate an improvement of English proficiency (Coleman, 1997). In this research, the more exposure the participants had to the English language environment, the more beneficial it was to their English improvement. The use of social strategies played a key 
Understanding Chinese graduate students' English language learning in a Canadian post-secondary context

role in all participants' efforts to be exposed to the English-speaking environment. Participants asked for assistance from proficient English speakers, interacted with them, and attempted to integrate into Canadian culture. However participants' narratives also revealed that found it difficult to have deep conversations with Canadians and to resonate with Canadians emotionally. Some participants suggested that these challenges could be traced to the differences between Chinese culture and Canadian culture. These cultural differences manifested mainly in terms of values, which was reflected in the difficulty faced by Chinese students in having unhindered communication with Canadians. For instance, some participants found it difficult to find common topics with their Canadian friends during conversations. Even with common topics, participants still discovered the huge difference in culture was a hindrance to their interactions with Canadians. For these participants, the differences in culture led them to seek emotional support from Chinese friends since they felt more comfortable when they stayed within the Chinese community. But they did not think this would have detrimental influence on their English improvement in Canada because they were capable of balancing their time between Chinese friends and mingling with Canadians.

\subsection{Differences between Strategies Used in China and Strategies Used in Canada}

These participants changed their English learning strategies after moving to Canada. Table 1 demonstrates the varied strategies used by participants in China and Canada.

\section{Table 1}

Participants' choice of English learning strategies in two different contexts

\begin{tabular}{|c|c|c|c|c|c|c|}
\hline Strategies & $\begin{array}{c}\text { Memory } \\
\text { strategies }\end{array}$ & Cognitive & Compensation & Meta-cognitive & Affective & Social \\
\hline China (EFL) & $\begin{array}{l}\text { Placing new } \\
\text { words into a } \\
\text { context, } \\
\text { structured } \\
\text { reviewing }\end{array}$ & $\begin{array}{l}\text { Repeating, } \\
\text { practicing } \\
\text { naturalistically, } \\
\text { reasoning } \\
\text { deductively, } \\
\text { analyzing } \\
\text { expressions, } \\
\text { translating, } \\
\text { taking notes }\end{array}$ & $\begin{array}{l}\text { Using linguistic } \\
\text { clues }\end{array}$ & $\begin{array}{l}\text { Organizing, } \\
\text { setting goals and } \\
\text { objectives, } \\
\text { planning for a } \\
\text { language task, } \\
\text { seeking practice } \\
\text { opportunities }\end{array}$ & $\begin{array}{l}\text { Using music, } \\
\text { discussing your } \\
\text { feelings with } \\
\text { someone else }\end{array}$ & $\begin{array}{l}\text { Cooperating } \\
\text { with peers, } \\
\text { cooperating with } \\
\text { proficient users } \\
\text { of the new } \\
\text { language }\end{array}$ \\
\hline Canada (ESL) & $\begin{array}{l}\text { Placing new } \\
\text { words into a } \\
\text { context }\end{array}$ & $\begin{array}{l}\text { Practicing } \\
\text { naturalistically }\end{array}$ & $\begin{array}{l}\text { Using linguistic } \\
\text { clues, using } \\
\text { other clues, } \\
\text { using mime or } \\
\text { gesture, using a } \\
\text { circumlocution } \\
\text { or synonym, } \\
\text { asked others for } \\
\text { help }\end{array}$ & $\begin{array}{l}\text { Identifying the } \\
\text { purpose of a } \\
\text { language task, } \\
\text { planning for a } \\
\text { language task, } \\
\text { seeking practice } \\
\text { opportunities }\end{array}$ & $\begin{array}{l}\text { Taking risks } \\
\text { wisely, making } \\
\text { positive } \\
\text { statements }\end{array}$ & $\begin{array}{l}\text { Asking for } \\
\text { clarification or } \\
\text { verification, } \\
\text { asking for } \\
\text { correction in } \\
\text { conversation or } \\
\text { writing, } \\
\text { cooperating with } \\
\text { peers, } \\
\text { cooperating with } \\
\text { proficient users } \\
\text { of the new } \\
\text { language, } \\
\text { developing } \\
\text { cultural } \\
\text { understanding }\end{array}$ \\
\hline
\end{tabular}

As shown in this table, the first change adopted was to reduce the usage of memory strategies and cognitive strategies. Instead, compensation strategies and social strategies were central in participants' English improvement in Canada. They employed compensation strategies to guess the meanings of conversations or writings, as well as overcoming roadblocks to their interactions with proficient English speakers. These interactions were also facilitated by using social strategies. This shift in strategies was closely related to the decreasing number of English proficiency tests that participants undertook. English proficiency tests in China forced participants to focus on linguistic details. Memory strategies were defined as strategies for "storing and retrieving information" and cognitive strategies primarily for "understanding and producing the language" (Hong-Nam \& Leavell, 2006, p. 40). Thus, these two categories of strategies facilitated participants' command of linguistic details. However, in Canada, participants were not required to take any English proficiency tests but 
Wang, H., \& Cottrell, M.

were encouraged to practice English through everyday application because they needed to overcome roadblocks to educational success and social adjustment.

The second change identified through participants' narratives was their increasing willingness to make mistakes and take risks in English learning. Most participants were worried about making mistakes in spoken English during their first few months in Canada. Conversing with others in English was a daunting task for them because they felt embarrassed and frustrated when they made mistakes, leading to miscommunication. These participants had high expectations for accuracy, particularly in spoken English because of their previous work to acquire strong scores in English proficiency tests in China. They strove to make as few mistakes as possible during these tests as the high requirement for accuracy had put them under enormous pressure. Another reason was a lack of opportunities to practice spoken English in China. Inadequate practice weakened their courage to take risks in spoken English. However, after these participants moved to Canada, they gradually discovered that making mistakes was acceptable during interactions as long as others could understand what was said. And with more practice, these participants felt increasingly confident when speaking English. Therefore, they were willing to take risks when conversing with others in English and they felt less stressed about the accuracy of their English.

\subsection{Participants' Motivations to Improve English Proficiency in Canada}

All participants attributed their improvement in English proficiency to the changes in English learning strategies employed in Canada. Compensation strategies assisted them in understanding what others said and in overcoming limitations during interactions. Social strategies facilitated their incorporation of appropriate English and enabled them to practice English with proficient English users. These participants strove to improve their English proficiency in Canada by changing English learning strategies for various reasons. Gao (2003) stated that facilitating studying was a key contributor to Chinese students' motivation to change English learning strategies in foreign countries. Participant C's motivation for making these changes was inspired by her desire to study in Canada. She was the only doctoral student among participants and she consequently dealt with a large quantity of experimental data, participated in a multitude of research seminars, and read a large number of professional articles. To improve the performance in her research area, Participant $\mathrm{C}$ strove to remove language barriers in studying. Financially supported by the Chinese government, she would dedicate herself in her research area in China upon graduation. To access the most recent research in her area of specialization she would need to read English articles and participate in international conferences. Excellent English proficiency would be vital for Participant $\mathrm{C}$ to accomplish her academic goals.

In contrast, the motivation to be a permanent resident of Canada contributed to Participant E's changes in English learning strategies. This participant had planned to immigrate to a foreign country such as Canada during his university period. He understood that English proficiency was a key factor in his successful application for permanent resident status in Canada. Excellent English proficiency not only enabled him to acquire a high score in the language section of the application, but also assisted him in finding a promising job in Canada. Also, Participant A and Participant F were motivated to make the realization of their goals more enjoyable through improved English proficiency. Participant A was intrigued by Western art and classical music in China and upon moving to Canada she became interested in books about medicine. Participant $F$ was a fan of English computer games. The development of English proficiency enabled these two participants to pursue their interests more effectively and to derive greater enjoyment from them.

All participants showed a strong motivation to derive maximum benefit from the English-speaking environment in Canada. They cherished the opportunities to study and live in Canada, partly because they realized that not every Chinese student was qualified to study in a Canadian university. Additionally, many of their families had invested large sums of money to facilitate their education and living in Canada, and they felt an obligation to make the most of that support. Most importantly however, participants' desire to make best use the English-speaking Canadian environment to improve English proficiency was an explicit and significant 
Understanding Chinese graduate students' English language learning in a Canadian post-secondary context

aspect of their personal motivations for internationalization and, in some cases, was as important as their desire to attain a Canadian postsecondary degree.

\subsection{Transition from a Teacher-centered to a Learner-centered Mode}

Participants' English learning experiences in China suggest the prevalence of a teacher-centered pedagogical approach. Teachers played a dominant role in English classes and students typically followed teachers' instructions. As a consequence participants considered English classes offered at their schools to be monotonous and demotivating. An interesting finding of this study is that the participants did not feel lost or frustrated due to a lack of instructions from teachers or parents after moving to Canada. Gao (2006) stated that Chinese students depended on their teachers and parents to tell them how to learn English in China. The research of Amuzie and Winke (2009) discovered that without assistance from teachers, international students would feel lost at the beginning but would decreasingly rely on teachers to improve English after moving to English-speaking countries. However, the participants in this research responded effectively to this situation. Having realized the importance of managing their English learning through their own efforts during their study in Chinese universities, these experiences enabled them to adapt to the English learning environment in Canada without assistance from teachers or parents. In essence participants' English learning switched from the teacher-centered mode to learner-centered mode gradually since their first university period. They finally completed the transmission after moving to Canada, which means that they are capable of constructing knowledge of English and choosing the most effective learning strategies in their own ways. Despite the language barrier, these participants understood that the optimal way of improving English proficiency in Canada was to blend into the English-speaking environment and socialize with proficient English users. They enjoyed learning English in Canada also because they were not required to participate in high stakes English proficiency tests. Without the pressure of those tests, participants found it enjoyable to learn English in Canada.

\subsection{Participants' Opinions on the Efficiency of English Teaching in China}

All participants conceded that English teaching in China made contributed to the improvement of their English vocabulary, grammar, reading comprehension, and listening ability. For example, participants were capable of reading English articles and watching English movies with this foundation. However, Participant C and Participant $\mathrm{F}$ considered the traditional methods of teaching English to be excessively monotonous and demotivating and suggested that this made it difficult for them to gain proficiency. Additionally, all participants were disappointed about their inadequate spoken English ability as a result of Chinese teaching methods and all agreed that the system placed undue emphasis on linguistic details instead of practical skills.

Some participants engaged in formal English language classes in Canada. Participant F and Participant G attended a part-time spoken English course during the first term and Participant E engaged in a written English course. Compared with their classes in China, the English courses these participants attended in Canada provided a far greater diversity in the method of instruction and also had a more practical focus. In particular the courses featured a large amount of group activity where English learning occurred through collaboration with other group members. This method facilitated participants' adaptation to different accents and provided them with vital opportunities for interacting with others in English. Furthermore, the instructors designed various activities to strengthen what the students had learned and adjusted time in assigning tasks based on the interactions between instructors and students. Also, the courses emphasized teaching students the most commonly used English expressions, class presentation skills, and the differences between formal writing and informal writing. Participants greatly appreciated the contributions these classes made to enhance their spoken and written English proficiency.

\subsection{The Relationships among Three Factors}

An important finding of this research is that with the agency role of the different English learning strategies, 
the English-speaking context was a key contributor to improving participants' English proficiency. The research conducted by Cubillos, Chieffo, and Fan (2008) proved that international students being immersed in a target language speaking environment were more inclined to employ social strategies than when they were in home countries. Storch and Hill (2008) claimed that international students' English proficiency benefited from being immersed in an English-speaking environment.

In this research, the shift of English-learning context led to the changes of English learning strategies and this, in turn, led to improvement in English proficiency. The English-speaking environment stimulated the changes in English learning strategies, which led to the development of participants' English proficiency. The English-speaking environment provided a large number of opportunities for the participants to practice English naturalistically, to ask for assistance, and to interact with proficient English users. The supervisors, colleagues, and volunteers from some local organizations assisted these participants when they encountered difficulties in English learning. Through mingling with Canadians and other international students, these participants learned how to use English accurately and appropriately.

Furthermore, these participants strove to adapt to the English-speaking environment. Ample opportunities of practicing English and the strong motivation of improving English proficiency led these participants to employ different English learning strategies from what they used in their home country. They endeavored to practice English through interacting with proficient English users. If these participants were confronted with any difficulties during interactions, they would employ compensation strategies to overcome limitations. Some of them were shy because they were too worried about making mistakes to converse with others in English. But they gradually overcame the shyness and took initiative to converse with others. These changes of English learning strategies facilitated their incorporation of appropriate English, brought them more opportunities of mingling with proficient English users, and bolstered their confidence in using English. As a result, their English proficiency gradually improved.

\section{Conclusion}

In addition to documenting and analyzing shifts in strategic approaches to language acquisition in a specific context of post-secondary internationalization, findings of this research have implications for prospective Chinese international students, for English language educators in China, and for policy makers in Canadian universities. Participants' narratives point to some challenges and limitations in the way in which the English language is taught in China. Consequently, prospective Chinese students who plan to study in Canada (or other English-speaking environments) are advised to practice English with authentic English materials. Watching English TV plays, listening to English songs, and reading English newspapers are possible methods of engaging with spoken English despite the EFL context of China. In addition, becoming familiar with academic language and discipline-specific terminology in their chosen fields is vital to Chinese students' successful engagement with postsecondary internationalization in English-speaking contexts. Overcoming the fear and the shyness of conversing and socializing with proficient English speakers in Canada will also significantly enhance Chinese students' English improvement.

\subsection{Implications for English Educators in China}

Given the growing demand for English language instruction in China, and the likelihood of increasing numbers of Chinese students engaging in international educational experiences in English-speaking countries, findings of this study have potential to enhance the efficacy of both. In particular, it is advisable for English language educators in China to re-evaluate traditional pedagogical techniques, to adopt a greater variety of teaching strategies and to integrate multimedia technology into English classes. Additionally, these English educators should pay more attention to the importance of practical English skills, especially colloquial spoken English, instead of the current focus on preparing students for acquiring high scores on tests. Wherever possible, students should also be exposed to discipline-specific academic and technical terminology, as inadequacies in 
Understanding Chinese graduate students' English language learning in a Canadian post-secondary context

these areas constitute major challenge to the successful adaption of Chinese students to English-speaking post-secondary international contexts.

\subsection{Implications for Policy Makers in English-speaking Postsecondary Institutions}

This study also has significant implications for policy makers in English-speaking postsecondary institutions, for whom Chinese students will constitute the largest pool of potential international recruits for the foreseeable future. As evidenced by the experiences of participants in this study, although Chinese students who enroll in English-speaking universities must meet prescribed English language requirements, many of them nevertheless still encounter difficulty adjusting to the English-speaking social and academic environments. Participants also felt they did not receive adequate assistance from the university they attended in order to strengthen their English competency. An obvious insight from this research is the need for English-speaking institutions wishing to attract Chinese international students to recognize the importance of English language competency acquisition as an explicit and significant aspect of students' personal motivations for internationalization and to develop more systematic supports in this area to assist Chinese students' adaptations to the English language environment. Findings from this research on the learning strategies employed by Chinese students in ESL and EFL contexts can be mobilized to develop language upgrading supports appropriate to their needs and tailored to their particular learning styles. Insights from this research also highlight the importance of positive social and cultural experiences for international students, suggesting the need for receiving institutions to invest more resources to ensure that this particular dimension of international students' needs are met. As this research suggests, such evidence-based and student-centered approaches will become increasingly necessary in the intensifying competitive landscape of postsecondary internationalization.

\subsection{Implications for prospective Chinese Students}

In addition to documenting and analyzing shifts in strategic approaches to language acquisition in a specific context of post-secondary internationalization, findings of this research have implications for prospective Chinese international students, for English language educators in China, and for policy makers in Canadian universities. Participants' narratives point to some challenges and limitations in the way in which the English language is taught in China. Consequently, prospective Chinese students who plan to study in Canada (or other English-speaking environments) are advised to practice English with authentic English materials. Watching English TV plays, listening to English songs, and reading English newspapers are possible methods of engaging with spoken English despite the EFL context of China. In addition, becoming familiar with academic language and discipline-specific terminology in their chosen fields is vital to Chinese students' successful engagement with postsecondary internationalization in English-speaking contexts. Overcoming the fear and the shyness of conversing and socializing with proficient English speakers in Canada will also significantly enhance Chinese students' English improvement.

\subsection{Implications for English Educators in China}

Given the growing demand for English language instruction in China, and the likelihood of increasing numbers of Chinese students engaging in international educational experiences in English-speaking countries, findings of this study have potential to enhance the efficacy of both. In particular, it is advisable for English language educators in China to re-evaluate traditional pedagogical techniques, to adopt a greater variety of teaching strategies and to integrate multimedia technology into English classes. Additionally, these English educators should pay more attention to the importance of practical English skills, especially colloquial spoken English, instead of the current focus on preparing students for acquiring high scores on tests. Wherever possible, students should also be exposed to discipline-specific academic and technical terminology, as inadequacies in these areas constitute major challenge to the successful adaption of Chinese students to English-speaking post-secondary international contexts. 
Wang, H., \& Cottrell, M.

\subsection{Implications for Policy Makers in English-speaking Postsecondary Institutions}

This study also has significant implications for policy makers in English-speaking postsecondary institutions, for whom Chinese students will constitute the largest pool of potential international recruits for the foreseeable future. As evidenced by the experiences of participants in this study, although Chinese students who enroll in English-speaking universities must meet prescribed English language requirements, many of them nevertheless still encounter difficulty adjusting to the English-speaking social and academic environments. Participants also felt they did not receive adequate assistance from the university they attended in order to strengthen their English competency. An obvious insight from this research is the need for English-speaking institutions wishing to attract Chinese international students to recognize the importance of English language competency acquisition as an explicit and significant aspect of students' personal motivations for internationalization and to develop more systematic supports in this area to assist Chinese students' adaptations to the English language environment. Findings from this research on the learning strategies employed by Chinese students in ESL and EFL contexts can be mobilized to develop language upgrading supports appropriate to their needs and tailored to their particular learning styles. Insights from this research also highlight the importance of positive social and cultural experiences for international students, suggesting the need for receiving institutions to invest more resources to ensure that this particular dimension of international students' needs are met. As this research suggests, such evidence-based and student-centered approaches will become increasingly necessary in the intensifying competitive landscape of postsecondary internationalization.

\section{References}

Alhaisoni, E. (2012). Language learning strategy use of Saudi EFL students in an intensive English learning context. Asian Social Science, 8(13), 115-127. http://dx.doi.org/10.5539/ass.v8n13p115

Amuzie, G. L., \& Winke, P. (2009). Changes in language learning beliefs as a result of study abroad. System, 37, 366-379. http://dx.doi.org/10.1016/j.system.2009.02.011

Bakhtin, M. M. (1981). The dialogic imagination: Four essays. Austin, TX: University of Texas Press.

Bremner, S. (1999). Language learning Strategies and Language Proficiency: Investigating the Relationship in Hong Kong. The Canadian Modern Language Review, 55(4), 490-514. http://dx.doi.org/10.3138/cmlr.55.4.490

Cadd, N. (2012). Encourage students to engage with native speakers during study abroad. Foreign Language Annals, 45(1), 229-245. http://dx.doi.org/10.1111/j.1944-9720.2012.01188.x

Carson, J. G., \& Longhini, A. (2002). Focusing on learning styles and strategies. Philadelphia: Open University Press.

Coleman, J. A. (1997). State of the art article: Residence abroad within language study. Language Teaching, 30(1), 1-20. http://dx.doi.org/10.1017/S0261444800012659

Cubillos, J. H., Chieffo, L., \& Fan, C. (2008). The impact of short-term study abroad programs on L2 listening comprehension skills. Foreign Language Annals, 41(1), 157-185. http://dx.doi.org/10.1111/j.1944-9720.2008.tb03284.x

Ellis, R. (1994). The study of second language acquisition. Oxford: Oxford University Press.

Fischer, K. (2013). A freshman year, far from home. Chronicle of Higher Education, 60(1), 23-23.

Gan, Z., Humphreys, Gillian., \& Hamp-Lyons, L. (2004). Understanding successful and unsuccessful EFL students in Chinese universities. The Modern Language Journal, 88, 229-244. http://dx.doi.org/10.1111/j.0026-7902.2004.00227.x

Gao, X. (2003). Changes in Chinese students' learner strategy use after arrival in the UK: a qualitative inquiry. In D. Palfreyman \& R. C. Smith (Eds.), Learner autonomy across cultures: Language education perspectives (pp. 41-57). Basingstoke: Palgrave Macmillan.

Gao, X. (2006). Understanding changes in Chinese students' uses of learning strategies in China and Britain: A socio-cultural re-interpretation. System, 34(1), 55-67. http://dx.doi.org/10.1016/j.system.2005.04.003

Green, J. M., \& Oxford, R. L. (1995). A closer look at learning strategies, L2 proficiency, and gender. TESOL 
Understanding Chinese graduate students' English language learning in a Canadian post-secondary context

Quarterly, 29, 261-297. http://dx.doi.org/10.2307/3587625

Griffiths, C. (2008). Lessons from good language learners. Cambridge: Cambridge University Press. http://dx.doi.org/10.1017/CBO9780511497667

Hong-Nam, K., \& Leavell, A. G. (2006). Language learning strategy use of ESL students in an intensive English learning context. System, 34(3), 399-415. http://dx.doi.org/10.1016/j.system.2006.02.002

Jin, Y., \& Yang, H. (2006). The English proficiency of college and university students in China: As reflected in the CET. Language, Culture, and Curriculum, 19(1), 21-36. http://dx.doi.org/10.1080/07908310608668752

Kojic-Sabo, I., \& Lightbown, P. M. (1999). Students' approaches to vocabulary learning and their relationship to success. The Modern Language Journal, 83(2), 176-192. http://dx.doi.org/10.1111/0026-7902.00014

Lee, D. S. (1997). What teachers can do to relieve problems identified by international students. New Directions for Teaching and Learning, 70, 93-100. http://dx.doi.org/10.1002/t1.7011

Lewthwaite, M. (1996). A study of international students' perspectives on cross-cultural adaptation. International Journal for the Advancement of Counselling, 19(2), 167-85. http://dx.doi.org/10.1007/BF00114787

Li, J. (2002). An empirical study on learning strategies of Chinese ESL learners. Foreign Language Education, 23(1), $42-48$.

Liu, L. (2011). An international graduate student's ESL learning experience beyond the classroom. TESL Canada Journal, 29(1), 77-92.

Ma, H., \& Lin, J. (2013). How Chinese exchange students adapt to their academic course learning in a US university: A fresh look at college English teaching in china. Cross-Cultural Communication, 9(3), 67-74.

Magno, C. (2010). Korean students' language learning strategies and years of studying English as predictors of proficiency in English. TESOL Journal, 2, 39-61.

McIntyre, P. D. (1994). Toward a social psychological model of strategy use. Foreign Language Annals, 27, 185-195. http://dx.doi.org/10.1111/j.1944-9720.1994.tb01201.x

Mochizuki, A. (1999). Language learning strategies used by Japanese university students. RELC Journal, 30(2), 101-113. http://dx.doi.org/10.1177/003368829903000206

Oxford, R. L. (1990). Language learning strategies: What every teacher should know. New York: Newbury House.

Pan, L., \& Block, D. (2011). English as a "global language" in China: An investigation into learners' and teachers' language beliefs. System, 39, 391-402. http://dx.doi.org/10.1016/j.system.2011.07.011

Pellegrino Aveni, V. (2005). Study abroad and second language use: Constructing the self. Cambridge, England: Cambridge University Press. http://dx.doi.org/10.1017/CBO9780511620584

Qingquan, N., Chatupote, M., \& Teo, A. (2008). A deep look into learning strategy use by successful and unsuccessful students in the Chinese EFL learning context. RELC Journal, 39(3), 338-358. http://dx.doi.org/10.1177/0033688208096845

Rao, Z. (2002). Chinese students' perceptions of communicative and non-communicative activities in EFL classroom. System, 30, 85-105. http://dx.doi.org/10.1016/S0346-251X(01)00050-1

Rao, Z. (2006). Understanding Chinese students' use of language learning strategies from cultural and educational perspectives. Journal of Multilingual and Multicultural Development, 27(6), 491-508. http://dx.doi.org/10.2167/jmmd449.1

Rivera-Mills, S. V., \& Plonsky, L. (2007). Empowering students with language learning strategies: A critical review of current issues. Foreign Language Annals, 40(3), 535-548.

http://dx.doi.org/10.1111/j.1944-9720.2007.tb02874.x

Rochecouste, J., Oliver, R., \& Mulligan, D. (2012). English language growth after university entry. International Journal of Educational Research, 53, 1-8. http://dx.doi.org/10.1016/j.ijer.2011.11.005

Scovel, J. (1983). English teaching in China: A historical perspective. Language Learning and Communication, 2(1), 105-109.

Segalowitz, N., Freed, B., Collentine, J.. Lafford, B., Lazar, N., \& Diaz-Campos, M. (2004). A comparison of Spanish second language acquisition in two different learning contexts: Study abroad and the domestic 
Wang, H., \& Cottrell, M.

classroom. Frontiers: The Interdisciplinary Journal of Study Abroad, 10, 1-18.

Senyshyn, R. M., Warford, M. K., \& Zhan, J. (2000). Issues of adjustment to higher education: International students' perspectives. International Education, 30(1), 17-35.

Storch, N., \& Hill, K. (2008). What happens to international students' English after one semester at university? Australian Review of Applied Linguistics, 31(1), 1-17. http://dx.doi.org/10.2104/aral0804

Takeuchi, O. (2003). What can we learn from good foreign language learners? A qualitative study in the Japanese foreign language context. System, 31(3), 385-392. http://dx.doi.org/10.1016/S0346-251X(03)00049-6

Vidal, R. J. (2002). Is there a correlation between reported language learning strategy use, actual strategy use and achievement? Linguagem \& Ensino, 5(1), 43-73.

Wong, L. L. C., \& Nunan, D. (2011). The learning styles and strategies of effective language learners. System, 39, 144-163. http://dx.doi.org/10.1016/j.system.2011.05.004

$\mathrm{Xu}, \mathrm{X}$. (2003). Rujia wenhua chuantong dui shisheng guanxi de fumian yingxiang. [The negative influence of traditional Confucianism on relationship between teachers and students]. Jin Yang Xue Kan, 4, 36-38.

Yang, D., \& Gai, F. (2010). Chinese learners' communication strategies research. Cross-Cultural Communication, 6(1), 56-81.

Yu, C. (1984). Cultural principles underlying English teaching in China. Language Learning and Communication, 3(1), 29-39.

Zhou, Y. (2012). Listening to voices: Understanding Chinese students' journey at a Canadian university. Master of Education. University of Saskatchewan, Saskatoon, SK. Retrieved from http://ecommons.usask.ca/bitstream/handle/10388/ETD-2012-03-410/ZHOU-THESIS.pdf?sequence=6 